\title{
BEHAVIOUR OF BITUMINOUS CONCRETE MODIFIED WITH POLYETHYLENE GLYCOL FOR BLADE AND DISK SHAPED AGGREGATES
}

\author{
T. Srikanth ${ }^{1}$, U. Arun Kumar ${ }^{2}$ \\ ${ }^{I}$ M. Tech Student, ${ }^{2}$ Associate Professor, Department of Civil Engineering, GMR Institute of Technology (A), Rajam - \\ 532127, Andhra Pradesh, India
}

\begin{abstract}
Aggregates are the principle material in pavement construction. Conventional road aggregates in India are natural aggregates obtained by crushing rocks. Aggregate characteristics such as particle size, shape, and texture etc.., influence the performance and serviceability of pavement. Pavements laid with polymer modified bitumen exhibits greater resistance to rutting, thermal cracking and fatigue damages and hence these were used at locations of higher stress. The present work concentrates on aggregate characteristics which include the shape indices. The particle shapes namely Blade and Disk are being used in the study. The study shows the behavior of the two shapes of aggregate in terms of Penetration, Ductility, Softening Point and Marshall Stability tests with varying percentages of bitumen and also with varying the percentages of PEG. The results of unmodified bitumen mix are compared with the modified bitumen mix against some critical Marshall Mix parameters.
\end{abstract}

Keywords: Shape of the aggregates, Bitumen modified with polymers, PEG, Stability and Flow of bitumen.

\section{INTRODUCTION}

\subsection{Aggregates}

Aggregates are crystalline or granular rocks that are extracted from natural rock for use in the construction industry. These can be either primary aggregates (extracted from the ground in quarries) or secondary aggregates (recycled from construction waste). Aggregates are an essential material in constructing and repairing entities such as roads, railways and buildings. The aggregates used in this study were separated firstly based on the size and secondly based on the shape (Blade and Disk).

\subsection{Bitumen}

The term bituminous materials are generally used to denote substances in which bitumen is present or from which it can be derived. Bitumen is defined as an amorphous, black or darkcolored, (solid, semi-solid, or viscous) cementetious substance, composed principally of high molecular weight hydrocarbons, and soluble in carbon disulfide.

Bitumen may occur in nature (natural bitumen) or may be obtained from petroleum processing (petroleum bitumen). Bituminous mixtures are generally used to denote the combinations of bituminous materials (as binders), aggregates and additives.

\subsection{Polyethylene Glycol (PEG)}

Polyethylene glycols, also called macro gels, these are manufactured by polymerization of ethylene oxide (EO) with water, mono ethylene glycol or diethylene glycol as starting material, under alkaline catalysis. After the desired molecular weight is reached (usually checked by viscosity measurements as in-process control) the reaction is terminated by neutralizing the catalyst with acid. Normally lactic acid is used, but also acetic acid or others can be found.

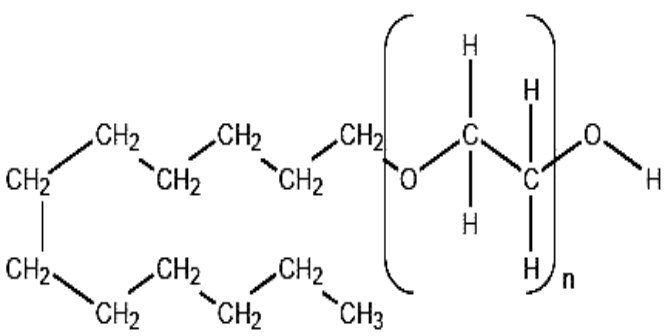

Fig -1: Chemical structure of PEG

The Chemical equation of PEG is:

$\mathrm{HO}-\mathrm{CH}_{2}-\left(\mathrm{CH}_{2}-\mathrm{O}-\mathrm{CH}_{2}\right)_{\mathrm{n}}-\mathrm{CH}_{2}-\mathrm{OH}$ 


\section{MATERIALS USED}

In this present work, the materials such as Aggregates (Coarse and Fine), Bitumen and PEG were used.

Aggregates of size $20 \mathrm{~mm}, 16 \mathrm{~mm}, 12.5 \mathrm{~mm}, 10 \mathrm{~mm}$ and $4.75 \mathrm{~mm}$ were procured from Rapaka a place nearer to Rajam town located in Srikakulam District - Andhra Pradesh. All these aggregates of different sizes were sieved and segregated by taking their shape, length, width and thickness into consideration.

Bitumen of 60/70 grade was procured from HPCL refinery, Vizag - Andhra Pradesh.

PEG was procured from RFCL Industry, New Delhi.

\section{TESTS PERFORMED AND THEIR RESULTS}

\subsection{Tests on Aggregates}

After the sorting of aggregate based on shape, tests such as Los Angeles Abrasion Value, Aggregate Crushing Value, Aggregate Impact Value, Specific Gravity and Water Absorption, Elongation Index and Flakiness Index were conducted to find out the properties of the aggregate. The results of above tests were shown in Table -3.1. Aggregate Shape Analysis was carried out as per one of the standard procedure and the results were shown in Table -3.2. A comparison graph for the above tests with respect to shape of the aggregate is shown in Chart -3.1.

Table -3.1: Results of tests done on aggregates

\begin{tabular}{||c|l|c|c||}
\hline \multirow{2}{*}{ Sl. No. } & \multicolumn{2}{|c|}{$\begin{array}{l}\text { Name of the } \\
\text { Experiment }\end{array}$} & \multicolumn{2}{|c|}{ Aggregate Shape } \\
\cline { 3 - 4 } & Llade & Disk \\
\hline \hline 1 & $\begin{array}{l}\text { Los Angeles } \\
\text { Abrasion value (\%) }\end{array}$ & 24.92 & 20.98 \\
\hline 2 & $\begin{array}{l}\text { Aggregate Crushing } \\
\text { Value (\%) }\end{array}$ & 36.35 & 32.97 \\
\hline 3 & $\begin{array}{l}\text { Aggregate Impact } \\
\text { value (\%) }\end{array}$ & 35.73 & 30.87 \\
\hline 4 & $\begin{array}{l}\text { Specific gravity \& } \\
\text { Water absorption of } \\
\text { Agg. }\end{array}$ & 2.68 & 2.66 \\
\hline 5 & EI + FI (\%) & 15.22 & 17.85 \\
\hline
\end{tabular}

\subsection{Shape of Aggregates}

Aggregate Shape Analysis was performed to know the Elongation Ratio, Flatness Ratio, Shape Factor and Sphericity of the aggregate based on the shape.

Elongation Ratio: It is the ratio of the intermediate diameter to the longest diameter of the aggregate.
Flatness Ratio: It is the ratio of the shortest diameter to the longest diameter of the aggregate.

Shape Factor: It is the ratio of the shortest diameter to the square root of intermediate and longest diameter of the aggregate.

Sphericity: It is a measure of how spherical (round) an object is. As such, it is a specific example of a compactness measure of a shape.

The following formulae's were used to calculate the above said two parameters.

$$
\text { Elongation ratio }=\frac{\mathrm{d}_{\mathbf{I}}}{\mathrm{d}_{\mathbf{L}}} \quad \text { Flatness ratio }=\frac{\mathrm{d}_{\mathrm{g}}}{\mathrm{d}_{\mathbf{L}}}
$$

$$
\text { Shape factor }=\frac{d_{s}}{\sqrt{d_{I} \times d_{L}}} \quad \text { Sphericity }=\sqrt[s]{\frac{d_{S} X d_{I}}{d_{L}{ }^{2}}}
$$

\subsection{Tests on Bitumen}

Tests such as Penetration Test, Softening Point Test and Ductility Test were conducted as per the standard procedure to find out the index properties of the bitumen (Unmodified and Modified). The results of above tests were shown in Table 3.3. A comparison graph for the above tests is shown in Chart -3.2 .

Table -3.3: Results of tests done on bitumen

\begin{tabular}{||l|l|l|l|l||}
\hline \hline Sl. No. & $\begin{array}{l}\text { \% } \\
\text { of } \\
\text { PEG }\end{array}$ & $\begin{array}{l}\text { Average } \\
\text { Penetration } \\
\text { value } \\
(\mathbf{1 / 1 0}) \mathbf{m m}\end{array}$ & $\begin{array}{l}\text { Average } \\
\text { Softening } \\
\text { Point } \\
\text { Temp. } \\
\left({ }^{\mathbf{0}} \mathbf{C}\right)\end{array}$ & $\begin{array}{l}\text { Average } \\
\text { Ductility } \\
(\mathbf{c m})\end{array}$ \\
\hline \hline 1 & 0.0 & 69.33 & 51.5 & 78.0 \\
\hline 2 & 0.5 & 67.67 & 52.5 & 82.0 \\
\hline 3 & 1.0 & 66.67 & 54.0 & 83.5 \\
\hline 4 & 1.5 & 66.00 & 56.0 & 85.5 \\
\hline 5 & 2.0 & 65.33 & 57.5 & 86.5 \\
\hline 6 & 2.5 & 64.00 & 59.5 & 87.0 \\
\hline
\end{tabular}

\subsection{Marshall Stability Test}

Marshall Stability Test was performed to find out the strength characteristics such as Stability, Flow, Unit Weight, OBC, etc. Marshall Samples were casted as per the standard specification of MORTH using unmodified bitumen for percentages of $3.0 \%, 3.5 \%, 4.0 \%$ and $4.5 \%$ and the same were tested. Samples of bitumen modified with PEG with $0.5 \%$, $1.0 \%, 1.5 \%, 2.0 \%$ and $2.5 \%$ for the above said bitumen percentages were also casted and tested where PEG content was taken by weight of Bitumen. 
Based on the results obtained from the Marshall Tests, comparison graphs were plotted for Stability, Flow, Unit Weight and Optimum Binder Content (OBC). Here Table 3.4, Table -3.5, Table -3.6 and Table -3.7 respectively shows the maximum value of Stability, Flow, Unit Weight and OBC obtained from the Marshall Test and the Chart -3.3, Chart -
3.4, Chart -3.5 and Chart -3.6 respectively shows the graphical representation of Stability, Flow, Unit Weight and $\mathrm{OBC}$. The tables and the figures were shown based on shape of aggregate and $\%$ of modifier used against a designated percentage of bitumen.

Table -3.2: Aggregate Shape Analysis test results

\begin{tabular}{|c|c|c|c|c|c|c|c|c|c|}
\hline Sl. No. & $\begin{array}{l}\text { Shape of the } \\
\text { aggregate }\end{array}$ & $\begin{array}{l}\text { Sieve size } \\
\quad(\mathrm{mm})\end{array}$ & $\begin{array}{c}\mathrm{dL} \\
(\mathbf{m m})\end{array}$ & $\underset{(\mathbf{m m})}{\text { dI }}$ & $\begin{array}{c}\mathrm{dS} \\
(\mathbf{m m})\end{array}$ & $\begin{array}{c}\text { Elongation } \\
\text { ratio }\end{array}$ & $\begin{array}{c}\text { Flatness } \\
\text { ratio }\end{array}$ & $\begin{array}{l}\text { Shape } \\
\text { factor }\end{array}$ & Sphericity \\
\hline \multirow{6}{*}{1} & \multirow{6}{*}{ Blade } & $25-20$ & 28.51 & 23.6 & 19.91 & 0.83 & 0.70 & 0.77 & 0.83 \\
\hline & & $20-16$ & 20.00 & 18.31 & 13.61 & 0.92 & 0.68 & 0.71 & 0.85 \\
\hline & & $16-12.5$ & 14.39 & 10.19 & 8.85 & 0.71 & 0.62 & 0.73 & 0.76 \\
\hline & & $12.5-10$ & 12.66 & 9.33 & 7.44 & 0.74 & 0.59 & 0.68 & 0.76 \\
\hline & & $10-4.75$ & 8.34 & 6.39 & 4.08 & 0.77 & 0.49 & 0.56 & 0.72 \\
\hline & & \multicolumn{4}{|c|}{ Average } & 0.79 & 0.61 & 0.69 & 0.78 \\
\hline \multirow{6}{*}{2} & \multirow{6}{*}{ Disk } & $25-20$ & 28.43 & 25.56 & 20.39 & 0.90 & 0.72 & 0.76 & 0.86 \\
\hline & & $20-16$ & 20.32 & 17.38 & 14.62 & 0.86 & 0.72 & 0.78 & 0.85 \\
\hline & & $16-12.5$ & 18.44 & 14.73 & 12.58 & 0.80 & 0.68 & 0.76 & 0.82 \\
\hline & & $12.5-10$ & 14.66 & 11.81 & 10.02 & 0.81 & 0.68 & 0.76 & 0.82 \\
\hline & & $10-4.75$ & 10.01 & 9.45 & 7.64 & 0.94 & 0.76 & 0.79 & 0.90 \\
\hline & & & Aver: & & & 0.86 & 0.71 & 0.77 & 0.85 \\
\hline
\end{tabular}

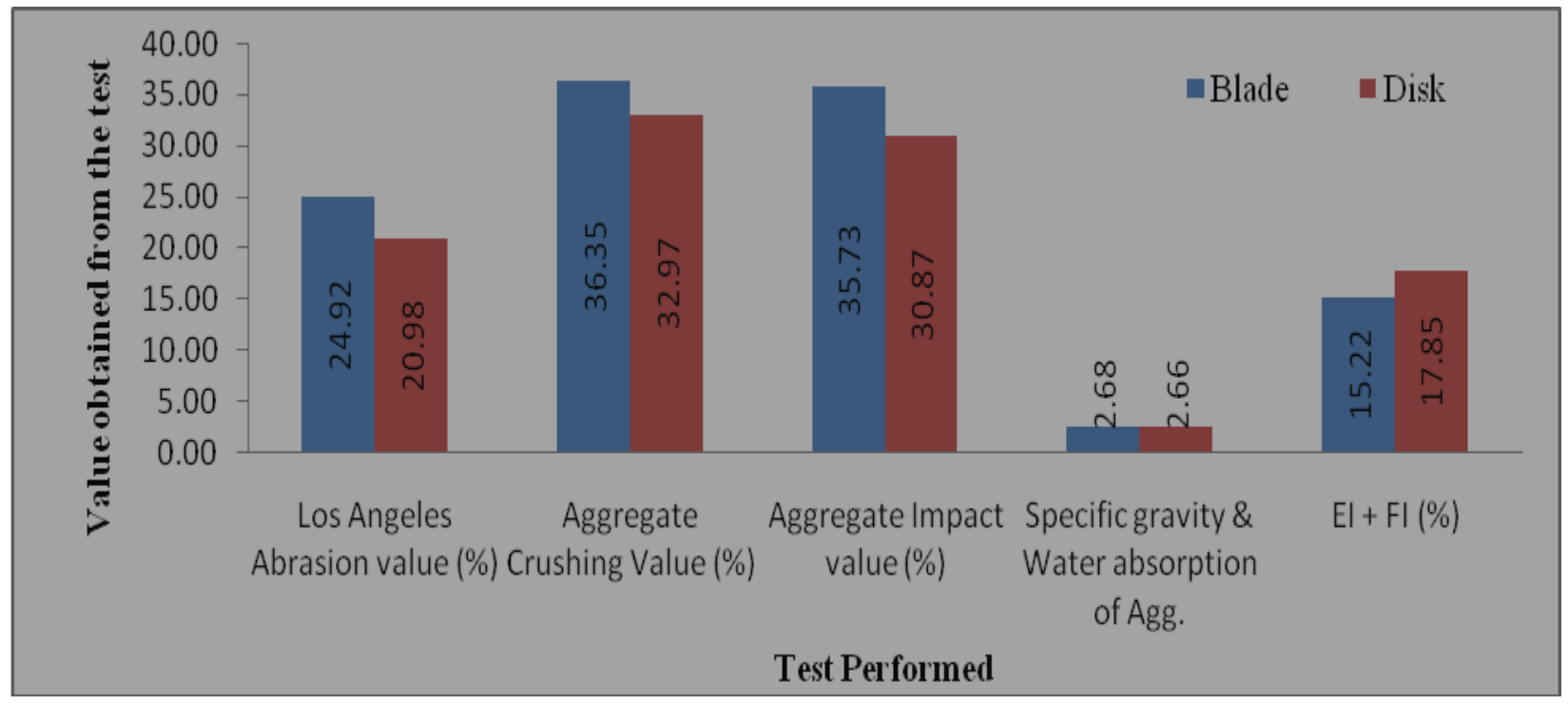

Chart -3.1: Graphical representation of the tests done on aggregates 


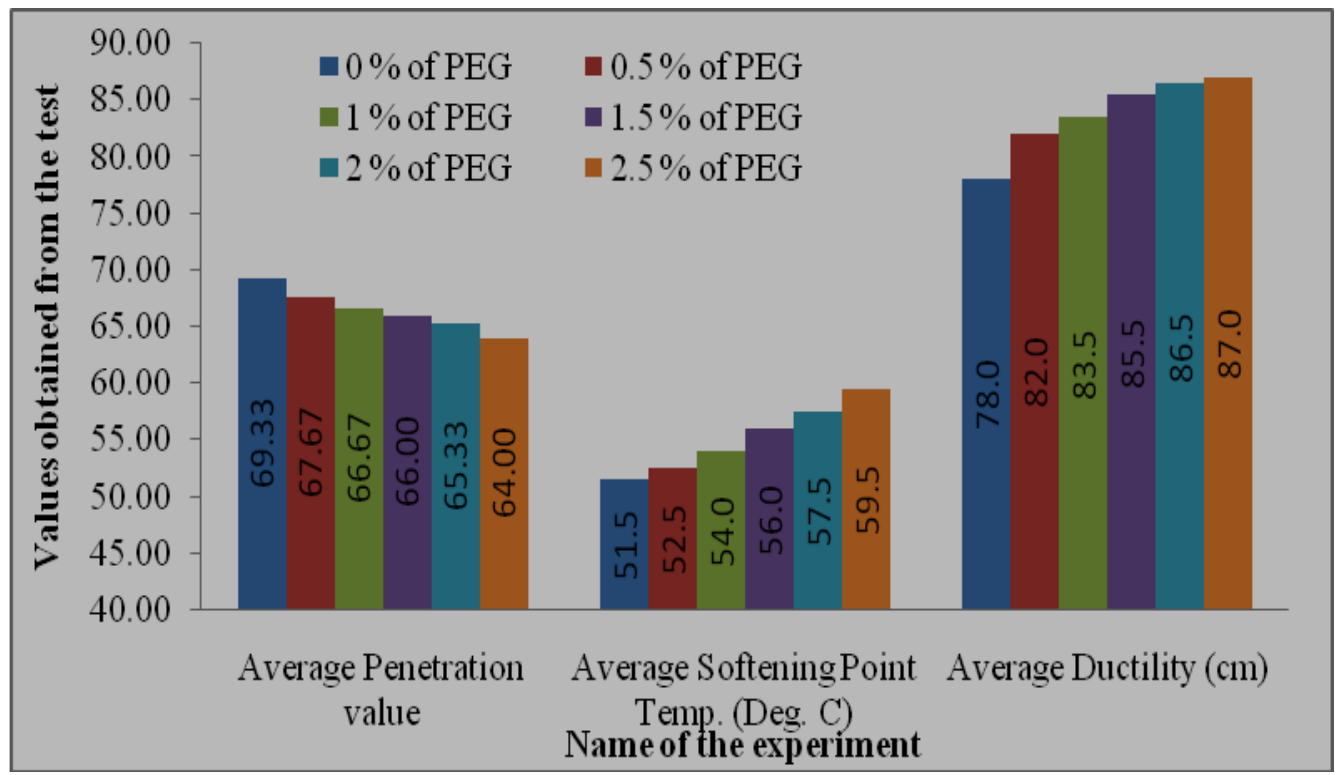

Chart -3.2: Graphical representation tests done on bitumen

Table -3.4: Maximum Stability $(\mathrm{kN})$ based on Shape and \% of modifier

\begin{tabular}{|c|c|c|c|c|}
\hline \multirow{2}{*}{ Sl. No. } & \multirow{2}{*}{$\begin{array}{c}\% \text { of } \\
\text { Bitumen }\end{array}$} & \multirow{2}{*}{$\%$ PEG } & \multicolumn{2}{|c|}{ Stability $(\mathbf{k N})$} \\
\hline & & & Blade & Disk \\
\hline 1 & \multirow{6}{*}{4.0} & 0.0 & 10.067 & 10.763 \\
\hline 2 & & 0.5 & 10.667 & 11.377 \\
\hline 3 & & 1.0 & 11.860 & 12.475 \\
\hline 4 & & 1.5 & 13.162 & 13.612 \\
\hline 5 & & 2.0 & 12.957 & 13.506 \\
\hline 6 & & 2.5 & 14.826 & 15.162 \\
\hline
\end{tabular}

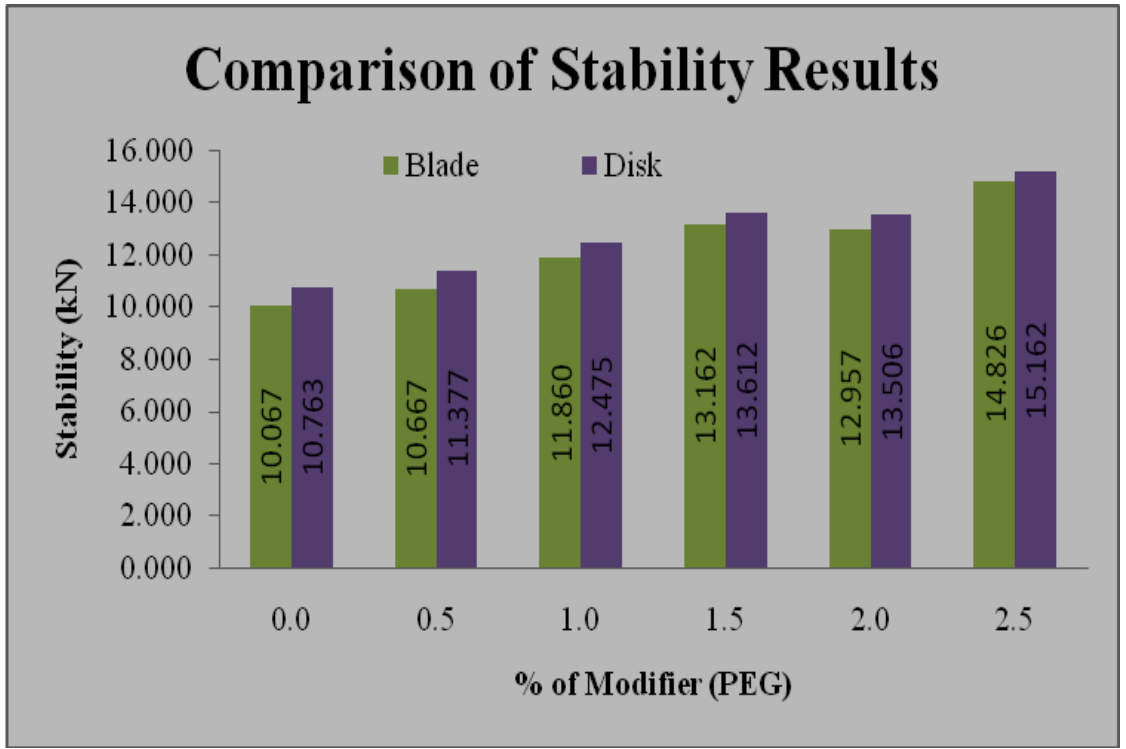

Chart -3.3: Maximum Stability $(\mathrm{kN})$ based on Shape and $\%$ of modifier 
Table -3.5: Maximum Flow $(\mathrm{mm})$ based on Shape and $\%$ of modifier

\begin{tabular}{|c|c|c|c|c|}
\hline \multirow{2}{*}{ Sl. No. } & \multirow{2}{*}{$\begin{array}{c}\% \text { of } \\
\text { Bitumen }\end{array}$} & \multirow{2}{*}{$\%$ PEG } & \multicolumn{2}{|c|}{ Flow (mm) } \\
\hline & & & Blade & Disk \\
\hline 1 & \multirow{6}{*}{4.5} & 0.0 & 1.992 & 2.304 \\
\hline 2 & & 0.5 & 2.150 & 2.463 \\
\hline 3 & & 1.0 & 2.375 & 2.638 \\
\hline 4 & & 1.5 & 2.800 & 2.988 \\
\hline 5 & & 2.0 & 2.625 & 2.850 \\
\hline 6 & & 2.5 & 3.375 & 3.513 \\
\hline
\end{tabular}

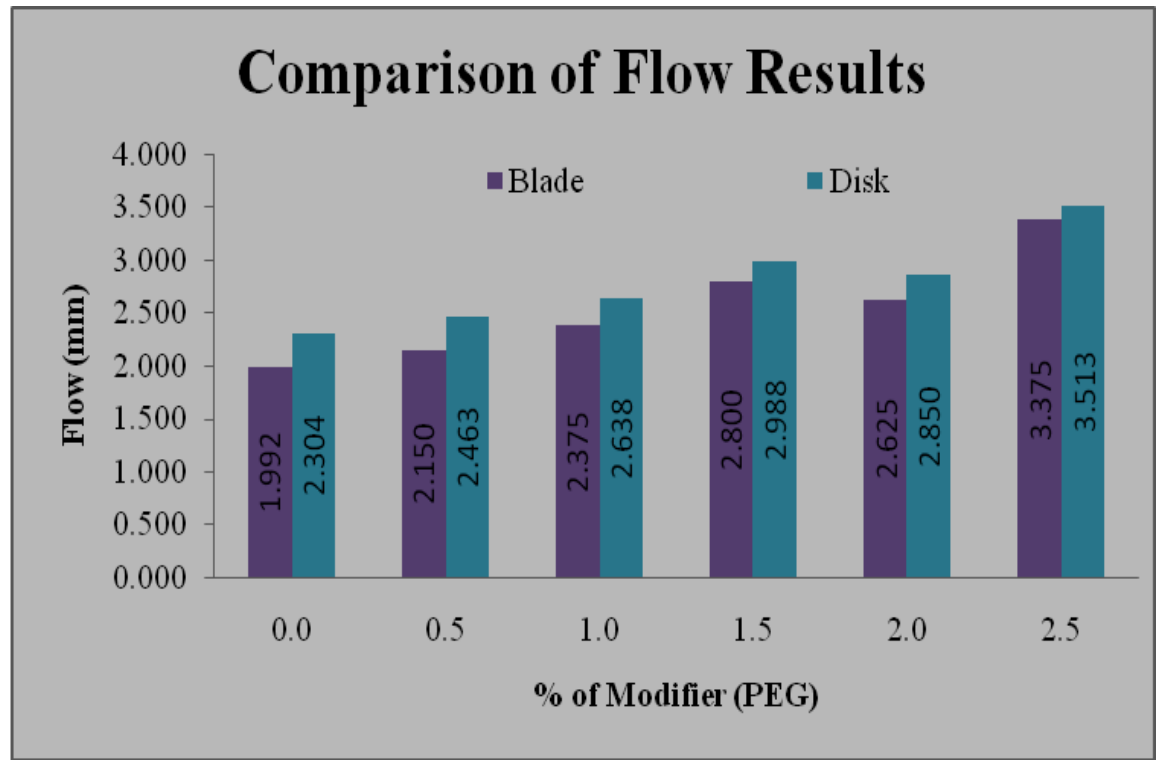

Chart -3.4: Maximum Flow (mm) based on Shape and \% of modifier

Table -3.6: Maximum Unit Weight $\left(\mathrm{kN} / \mathrm{m}^{3}\right)$ based on Shape and $\%$ of modifier

\begin{tabular}{|c|c|c|c|c|}
\hline \multirow{2}{*}{ Sl. No. } & \multirow{2}{*}{$\begin{array}{c}\text { \% of } \\
\text { Bitumen }\end{array}$} & \multirow{2}{*}{$\%$ PEG } & \multicolumn{2}{|c|}{ Unit Weight $\left(\mathrm{kN} / \mathrm{m}^{3}\right)$} \\
\hline & & & Blade & Disk \\
\hline 1 & \multirow{6}{*}{4.0} & 0.0 & 23.918 & 23.668 \\
\hline 2 & & 0.5 & 23.932 & 23.689 \\
\hline 3 & & 1.0 & 23.946 & 23.699 \\
\hline 4 & & 1.5 & 23.955 & 23.708 \\
\hline 5 & & 2.0 & 23.947 & 23.704 \\
\hline 6 & & 2.5 & 23.968 & 23.723 \\
\hline
\end{tabular}




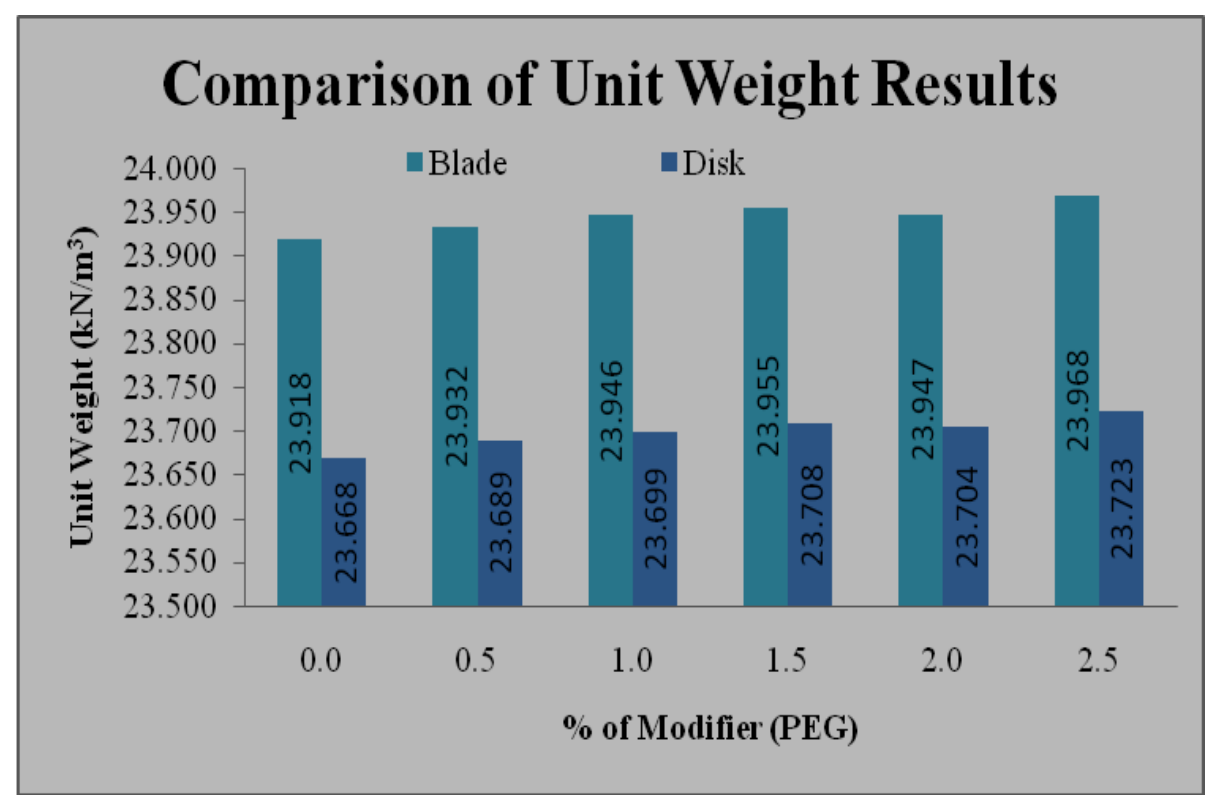

Chart -3.5: Maximum Unit Weight $\left(\mathrm{kN} / \mathrm{m}^{3}\right)$ based on Shape and \% of modifier

Table -3.7: Maximum OBC (\%) based on Shape and \% of modifier

\begin{tabular}{||c|c|c|c||}
\hline \multirow{2}{*}{ Sl. No. } & \multirow{2}{*}{ \% PEG } & \multicolumn{2}{|c|}{ OBC (\%) } \\
\cline { 3 - 4 } & & Blade & Disk \\
\hline \hline 1 & 0.0 & 3.95 & 3.98 \\
\hline 2 & 0.5 & 3.95 & 3.98 \\
\hline 3 & 1.0 & 4.02 & 4.04 \\
\hline 4 & 1.5 & 4.06 & 4.07 \\
\hline 5 & 2.0 & 4.03 & 4.05 \\
\hline 6 & 2.5 & 4.08 & 4.09 \\
\hline
\end{tabular}

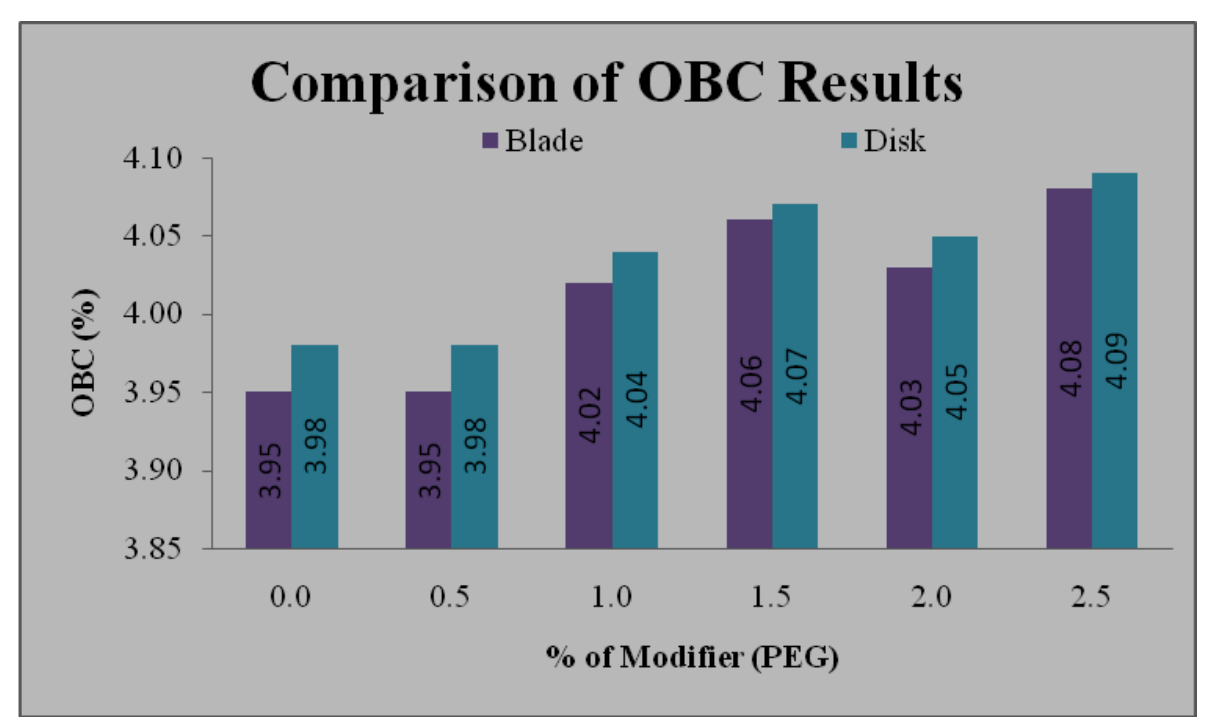

Chart -3.6: OBC (\%) based on Shape and \% of modifier 


\section{CONCLUSIONS}

1. It was observed that the Disk aggregates produced better results in Los Angeles Abrasion Test (20.98\%), Aggregate Crushing Value (32.97\%) and Aggregate Impact Test (30.87\%) when compared with Disk shape. The combined Elongation and Flakiness Index (15.22\%) shows better result in Blade shaped aggregates when compared with Disk shape.

2. It was observed that as the \% of PEG is increasing the Ductility and Softening Point test results were also increasing but quite obviously there is a decrease in the Penetration test which in turn matches with the standard trend.

3. The percentile increments of Marshall Properties for Blade shaped Aggregate:

Stability was increased as shown below i.e., 5.96\%, $17.81 \%, 30.74 \%, 28.70 \%$ and $47.27 \%$ when percentile of modifier is of $0.5,1,1.5,2$ and 2.5 respectively when compared with unmodified bitumen.

Flow was increased as shown below i.e., 7.93\%, 19.22\%, $40.56 \%, 31.77 \%$ and $69.42 \%$ when percentile of modifier is of $0.5,1,1.5,2$ and 2.5 respectively when compared with unmodified bitumen.

4. The percentile increments of Marshall Properties for Disk shaped Aggregate

Stability was increased as shown below i.e., 5.47\%, $14.21 \%, 22.69 \%, 22.63 \%$ and $35.23 \%$ when percentile of modifier is of $0.5,1,1.5,2$ and 2.5 respectively when compared with unmodified bitumen.

Flow was increased as shown below i.e., $6.03 \%, 10.81 \%$, $21.32 \%, 17.50 \%$ and $39.47 \%$ when percentile of modifier is of $0.5,1,1.5,2$ and 2.5 respectively when compared with unmodified bitumen.

\section{REFERENCES}

[1]. Amit gawande, G. S. Zamre, V. C. Renge, G. R. Bharsakalea and Saurabh Tayde (2012) Utilization of Waste Plastic in Asphalting of Roads, Scientific reviews and Chemical Communications, Volume 2, pp. $147-157$.

[2]. K. Lee, T. Park, R. Salgado, C. W. Lovell and B. J. Coree (1997) Use of Pyrolyzed Carbon Black as Additive in Hot Mix Asphalt, Journal of Transportation Engineering, pp. 489 494.

[3]. Meor Othman Hamzah, Marliana Azura Ahmad Puzi and Khairun Azizi Mohd Azizli (2010) Properties of Geometrically Cubical Aggregates and its Mixture Design, International Journal of Research and Reviews in Applied Sciences, Volume 3, pp. $249-256$.

[4]. Mutiu Akinpelu, Bamidele I. O. Dahunsi, Oladipupo Olafusi, Olufemi Awogboro and Adedeji Quadri (2013) Effect of Polythene Modified Bitumen on Properties of Hot Mix Asphalt, ARPN Journal of Engineering and Applied Sciences, Volume 8, pp. $290-295$.
[5]. P.K Jain, Ambika Behl and Girish Sharma (2012) Study on Waste Polyvinyl Chloride Modified Bitumen for Paving Applications, ARRB Conference, pp. $1-15$.

[6]. Seracettin Arasan, A.Samet Hasiloglu and Suat Akbulut (2010) Shape Properties of Natural and Crushed Aggregate using Image Analysis, International Journal of Civil and Structural Engineering, Volume 1, pp. $221-233$.

[7]. Bureau of Indian Standards (BIS) (1963), Methods of test for Aggregate for concrete, Part I Particle Shape and Size, IS: 2386 (Part-I), New Delhi, India.

[8]. Bureau of Indian Standards (BIS) (1963), Methods of test for Aggregate for concrete, Part III Specific Gravity, Density, Voids, Absorption and Bulking, IS: 2386 (Part - III), New Delhi, India.

[9]. Bureau of Indian Standards (BIS) (1963), Methods of test for Aggregate for concrete", Part IV Mechanical Properties, IS: 2386 (Part-IV), New Delhi, India.

[10]. Bureau of Indian Standards (BIS) (1978), Methods of testing Tar and Bituminous Material: Determination of Index properties of bitumen, IS: 1201 to 1220 - 1978, New Delhi, India.

\section{BIOGRAPHIES}

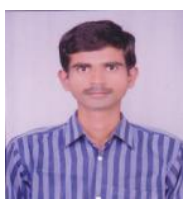

T. Srikanth, Pursuing M. Tech (Transportation Engineering) from Department of Civil Engineering, GMR Institute of Technology, An Autonomous Institute Affiliated to JNTU Kakinada, Rajam, Srikakulam District, Andhra Pradesh -532127 .

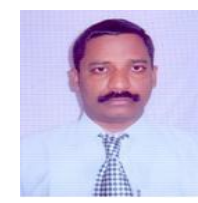

U. Arun Kumar, working as a Associate Professor in Department of Civil Engineering, GMR Institute of Technology, An Autonomous Institute Affiliated to JNTU Kakinada, Rajam, Srikakulam District, Andhra Pradesh - 532127. 